\title{
Imipenem dosing recommendations for patients undergoing continuous renal replacement therapy: systematic review and Monte Carlo simulations
}

Dhakrit Rungkitwattanakul ${ }^{1}$, Taniya Charoensareerat ${ }^{2}$, Pathakorn Kerdnimith ${ }^{2}$, Nutsinee Kosumwisaisakul ${ }^{2}$, Piyakamol Teeranaew2 ${ }^{2}$, Apinya Boonpeng ${ }^{3}$, Sutthiporn Pattharachayakul ${ }^{4}$, Nattachai Srisawat $5,6,7,8,9,10$ and Weerachai Chaijamorn ${ }^{2 *}$ (D)

\begin{abstract}
Background: The appropriate dosing of imipenem for critically ill AKI patients undergoing CRRT remains scarce.

Purpose: This study aimed to (1) gather the available published pharmacokinetic studies conducted in septic patients receiving continuous renal replacement therapy (CRRT) and (2) to define the optimal imipenem dosing regimens in these populations via Monte Carlo simulations.

Methods: The databases of PubMed, Embase, and ScienceDirect were searched from inception to May 2020. We used the Medical Subject Headings of "Imipenem," "CRRT," and "pharmacokinetics" or related terms or synonym to identify the studies for systematic reviews. A one-compartment pharmacokinetic model was conducted to predict imipenem levels for the initial $48 \mathrm{~h}$ of therapy. The pharmacodynamic target was $40 \%$ of free drug level above 4 times of the MIC (40\% fT > $4 \mathrm{MIC}$ ). The dose that achieved at least $90 \%$ of the probability of target attainment was defined as an optimal dose.
\end{abstract}

Results: Eleven articles were identified and included for our systematic review. The necessary pharmacokinetic parameters such as the volume of distribution and the CRRT clearance were mentioned in 100 and $90.9 \%$, respectively. None of the current studies reported the complete necessary parameters. A regimen of $750 \mathrm{mg} \mathrm{q} 6 \mathrm{~h}$ was the optimal dose for the predilution-CVVH and CVVHD modality with two effluent rates ( 25 and $35 \mathrm{~mL} / \mathrm{kg} / \mathrm{h}$ ) for the pharmacodynamic target of $40 \% \mathrm{fT}>4 \mathrm{MIC}$.

Conclusions: None of the current studies showed the complete necessary pharmacokinetic parameters for drug dosing. Pharmacodynamic target significantly contributed to imipenem dosing regimens in these patients. Different effluent rates and types of CRRT had minimal impact on dosing regimens. Clinical validation of the recommendation is necessary.

Keywords: Imipenem, Drug dosing, AKI, CRRT, Critically ill patients

*Correspondence: weerachai.cha@siam.edu

${ }^{2}$ Faculty of Pharmacy, Siam University, Bangkok, Thailand

Full list of author information is available at the end of the article

\section{Introduction}

In the critical care setting, both acute kidney injury (AKI) and critically ill are common complicating factors to therapeutic management. Anuric AKI patients may need therapeutic renal support by continuous renal original author(s) and the source, provide a link to the Creative Commons licence, and indicate if changes were made. The images or other third party material in this article are included in the article's Creative Commons licence, unless indicated otherwise in a credit line to the material. If material is not included in the article's Creative Commons licence and your intended use is not permitted by statutory regulation or exceeds the permitted use, you will need to obtain permission directly from the copyright holder. To view a copy of this licence, visit http://creativecommons.org/licenses/by/4.0/. The Creative Commons Public Domain Dedication waiver (http://creativeco mmons.org/publicdomain/zero/1.0/) applies to the data made available in this article, unless otherwise stated in a credit line to the data. 
replacement therapies (CRRT), which can further complicate drug dosing regimens. Imipenem is one of the carbapenem antibiotics possessing a broad spectrum of activity against many Gram-positive, Gram-negative aerobic, and anaerobic bacteria. In patients without history of renal impairment, the clearance of imipenem is $165-207 \mathrm{ml} / \mathrm{min}$ [1]. The volume of distribution (Vd) of imipenem in adults averages $0.23-0.35 \mathrm{~L} / \mathrm{kg}$ [2]. Due to its properties, imipenem is susceptible to be removed from CRRT treatments. In adult patients without renal impairment, the dosing recommendation of imipenem is $500-1,000 \mathrm{mg}$ given intravenous (IV) every 6-8 h (h), with the maximum daily dose of $4 \mathrm{~g}$ [3]. Though its use is often limited by the availability of other carbapenems, imipenem is still recommended as one of the first-line treatments by several society practice guidelines for the management of serious infections due to resistant pathogens [4-6]. Imipenem is often implicated with neurological side effects. However, recent reports showed that the risk of adverse effects remains low $(<0.2 \%)$ as long as the dose is appropriate [7]. Most patients who developed neurological toxicities had predisposing risk factors to increase brain permeability to imipenem [8]. Therefore, appropriate dosing to achieve therapeutic effect and to avoid adverse event is very important. Seyler et al. reported that in infected patients receiving CRRT, the recommended doses of several beta-lactams are inadequate to achieve pharmacodynamic targets [9]. However, the data reflecting dose recommendation for imipenem in patients undergoing CRRT are scarce.

Previous studies reported that free drug concentration for which exceeds the MIC for $40 \%$ of the dosing interval is essential for clinical success in using anti-infective therapy [10]. In our study, we aim to define the optimal dosing by utilizing Monte Carlo simulation to predict serum drug concentration based on available dosing regimens for patients undergoing CRRT. The optimal dose is referred to the regimen that is able to achieve probability of target attainment of $>90 \%$.

Several factors must be considered before selecting the imipenem dose for patients receiving CRRT. Both CRRT modality and intensity play major roles in drug clearance in CRRT [11]. An effluent flow rate of $25 \mathrm{ml} / \mathrm{kg} / \mathrm{h}$ is nowadays considered the most commonly used for critically ill patients with AKI [12]. However, in some cases, a high intensity $(35 \mathrm{ml} / \mathrm{kg} / \mathrm{h})$ flow rate can also be used. Chaijamorn et al. reported higher antibiotic clearance in AKI patients receiving high intensity continuous venovenous hemofiltration (CVVH) [13]. Therefore, studies recommending dosage regimens should provide important operational treatment characteristics for the clinicians to determine the similarities or differences in order to provide the accurate recommendation for the individual patient.

Thus, both antibiotic-related pharmacokinetics and CRRT-related operational characteristics are essential to make dosing recommendations. This systematic review is aimed to evaluate the sufficient data reporting in pharmacokinetic studies conducted in AKI patients receiving CRRT and to define the optimal imipenem dosing recommendation by Monte Carlo Simulation based on pharmacokinetic parameters derived from published studies.

\section{Methods}

\section{Search strategies}

The following databases were used to search for original research articles from November 1998 to May 2020: PubMed, Embase, and Science direct. We used the Medical Subject Headings (MeSH) of "Imipenem," "continuous renal replacement therapy," "pharmacokinetics," "continuous venovenous hemofiltration," "continuous venovenous hemodiafiltration," "continuous venovenous hemodialysis." We also manually searched the reference lists of the retrieved studies to identify additional studies for systematic reviews. The search was limited to human study and the English language.

\section{Study selection}

The articles were included if they were the traditional pharmacokinetics study of imipenem and conducted in the patient who received the continuous renal replacement therapy. The following criteria were excluded: (1) population pharmacokinetics, (2) intermittent hemodialysis (IHD) or sustained low-efficiency dialysis (SLED) pharmacokinetics studies, (3) concomitant use of Extracorporeal Membrane Oxygenation (ECMO) with CRRT, (4) non-English language article or review articles.

\section{Data extraction}

Two authors (TC and PK) independently extracted data using a data extraction form following the Preferred Reporting Items for Systematic Reviews and Meta-analyses (PRISMA) guideline. Disagreements between the independent researchers were resolved by discussions with a third independent researcher (WC).

\section{Main outcomes measurement}

Studies included in this review were assessed for sufficient data reporting in the septic patients receiving CRRT using the ideal dataset required from the previous study [14]. This dataset includes (1) Drug data: antibiotic assayed, specific pharmacodynamic target and dose recommendation, (2) Patient demographics: age, weight, the severity of illness, number of the patients in the study, residual renal function, and hepatic function, (3) Basic 
pharmacokinetics: volume of distribution (Vd), total clearance, CRRT clearance, non-CRRT clearance $\left(\mathrm{CL}_{\mathrm{NR}}\right)$, and protein binding or serum albumin, and (4) specific CRRT clearance parameters depended on CRRT mode:

- pre-dilution CVVH: sieving coefficient (SC), ultrafiltration rate $(\mathrm{Qf})$, blood flow rate $(\mathrm{Qb})$, hematocrit (Hct), and predilution replacement flow rate (Qpre)

- post-dilution CVVH: sieving coefficient (SC) and ultrafiltration rate (Qf)

- CVVHD: saturation coefficient (SA) and dialysis flow rate $(\mathrm{Qd})$

- CVVHDF: SC or Sd, ultrafiltration rate (Qf) and dialysis flow rate $(\mathrm{Qd})$ or effluent flow rate $(\mathrm{Qf}+\mathrm{Qd})$

The quality assessments were performed independently by two investigators (DR and TC). The percentage of each variable was calculated to describe the completion of data provided.

\section{Monte Carlo simulations and pharmacodynamic target}

The one-compartmental pharmacokinetic models of the first 48-h imipenem concentration for AKI receiving CRRT were developed based on the previous literature [15]. The necessary pharmacokinetic parameters from 11 studies of imipenem conducted in anuric or oliguric patients receiving CRRT were selected and included in the models [2, 16-25]. Blood flow rate of $200 \mathrm{~mL} / \mathrm{min}$ and hematocrit 30\% were used in our pharmacokinetic model. The infusion time of the drug was $0.5-\mathrm{h}$. The correlation $\left(r^{2}\right)$ between body weight and $\mathrm{Vd}$ or $\mathrm{CL}_{\mathrm{NR}}$ was input to the model to generate a population specific virtual patient. SA was obtained from a study included 35 patients receiving CVVHD. Due to its similar principle, we decided to incorporate the SA obtained from two hemodialysis studies, for a total of 54 patients to improve the generalizability. Free fraction of imipenem in plasma was also obtained and incorporated into the model [3].

Based on Kidney Disease: Improving Global Outcomes (KDIGO) recommendation, ultrafiltration, or dialysate flow rates of $25 \mathrm{~mL} / \mathrm{kg} / \mathrm{h}$ were used in the pre-hemofilter dilution CVVH and CVVHD models, respectively [12]. High CRRT intensity, the ultrafiltration, or dialysate flow rates of $35 \mathrm{~mL} / \mathrm{kg} / \mathrm{h}$, which were represented to the common effluent flow rate in clinical practice, were also used in this simulation [26].

The drug concentration-time profile of 5000 virtual patients was created by Monte Carlo simulation (Oracle Crystal Ball Classroom) [11, 27]. In this study, the pharmacodynamic targets of $40 \%, 100 \%$ of unbound fraction of drug level above the MIC ( $40 \% \mathrm{fT}>\mathrm{MIC}, 100 \%$ $\mathrm{fT}>\mathrm{MIC}$ ), and $40 \%$ of unbound fraction of drug level above 4 times of the MIC ( $40 \% \mathrm{fT}>4 \mathrm{MIC})$ were studied.
The MIC breakpoint of $2 \mathrm{mg} / \mathrm{L}$ based on Clinical and Laboratory Standards Institute (CLSI) was chosen for susceptible Pseudomonas aeruginosa [28]. The proportion of patients that attain the pharmacodynamic (PD) target was calculated as the probability of target attainment (PTA). The optimal dosage regimens were considered when the lowest dose was able to achieve the PTA at least $90 \%$.

To calculate drug concentration profile, the equations used in the model were the following:

$$
\begin{aligned}
\mathrm{CL}_{\mathrm{HD}}(\mathrm{L} / \mathrm{h}) & =\mathrm{SA}^{*} \mathrm{Qd} \\
\mathrm{CL}_{\mathrm{HF}}(\mathrm{L} / \mathrm{h}) & =\mathrm{SC}^{*} \mathrm{Q}_{\mathrm{uf}}^{*}\left[\mathrm{Q}_{\text {plasma }} / \mathrm{Q}_{\text {plasma }}+\mathrm{Q}_{\text {replacement }}\right] \\
\mathrm{Vd} & =\mathrm{Vd}(\mathrm{L} / \mathrm{kg}){ }^{*} \mathrm{Wt}(\mathrm{kg}) \\
\mathrm{k}_{\mathrm{e}} & =\left(\mathrm{CL}_{\mathrm{NR}}+\mathrm{CL}_{\mathrm{HD}}\right) / \mathrm{Vd} \\
\mathrm{k}_{\mathrm{e}} & =\left(\mathrm{CL}_{\mathrm{NR}}+\mathrm{CL}_{\mathrm{HF}}\right) / \mathrm{Vd}
\end{aligned}
$$

where $\mathrm{CL}_{\mathrm{HF}}$ is the transmembrane clearance in hemofiltration; $\mathrm{SC}$ is sieving coefficient; $\mathrm{Q}_{\mathrm{uf}}$ is the ultrafiltrate flow rate; $Q_{\text {plasma }}$ is the plasma flow rate $\left(\mathrm{Q}_{\text {plasma }}=\mathrm{Q}_{\text {blood }}{ }^{*}(1-\right.$ hematocrit $) ; \quad$ hematocrit is $30 \%) ; \mathrm{Q}$ replacement is the replacement fluid flow rate $\left(\mathrm{Q}_{\text {replacement }}=\mathrm{Q}_{\mathrm{uf}}\right) ; C \mathrm{~L}_{\mathrm{HD}}$ is the transmembrane clearance in hemodialysis; SA is the saturation coefficient; $Q_{d}$ is the dialysate flow rate; $\mathrm{Vd}$ is the volume of distribution; Wt $(\mathrm{kg})$ is the body weight; $\mathrm{k}_{\mathrm{e}}$ is the elimination rate constant.

\section{Results}

The study selection chart is shown in Fig. 1. The literature search yielded 148 studies related to our search terms. Duplicated and irrelevant studies were eliminated via screening from two independent pharmacists. As a result, 16 articles were eligible for full-text assessment. Only 11 studies met the inclusion criteria and included in the assessment for completion of the pharmacokinetic parameters (Table 1). All studies are based on prospective data and included patients undergoing CRRT. The studies included were published from 1989 to 2019.

\section{Main outcome assessment}

Notably, none of the included studies reported completion of necessary pharmacokinetic parameters.

\section{Drug data}

All studies reported drug assay. Most studies reported dose recommendations; however, only $22 \%$ reported prespecified pharmacodynamic target. None of the studies reported the free fraction of imipenem in the plasma (Fig. 2a). 


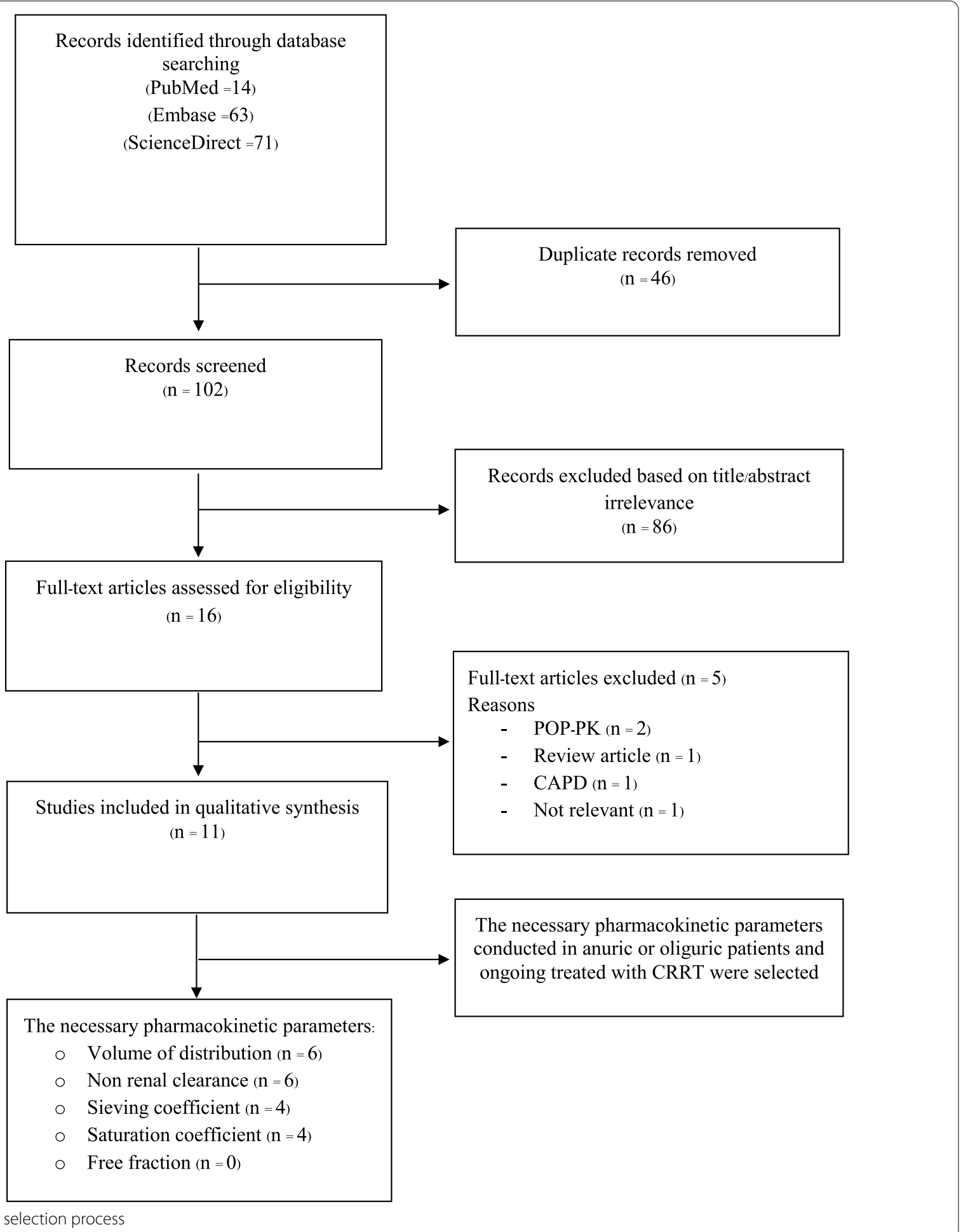

Fig. 1 Study selection process

\section{Patient demographics}

Most studies reported age and sample size of the studied population. About $80 \%$ of studies described residual renal function. Less than $10 \%$ reported hepatic function (Fig. 2b). 
Table 1 Key characteristics of published pharmacokinetics studies of imipenem in critically ill patients undergoing CRRT [2, 9-18]

\begin{tabular}{|c|c|c|c|c|c|c|c|}
\hline References & CRRT mode & SC or SA & $\mathrm{Vd}(\mathrm{L} / \mathrm{kg})$ & $\mathrm{CL}_{\mathrm{NR}}(\mathrm{ml} / \mathrm{min})$ & $\mathrm{CL}_{\mathrm{CRRT}}(\mathrm{ml} / \mathrm{min})$ & $\begin{array}{l}\text { Pre- } \\
\text { specified } \\
\text { PD target }\end{array}$ & $\begin{array}{l}\text { Dose } \\
\text { recommendation }\end{array}$ \\
\hline Keller et al. [20] & CAVH & 1.16 & 0.29 & $108.5 \pm 29.6$ & $7.0 \pm 3.4$ & NS & NS \\
\hline Przechera et al. [16] & $\mathrm{CAVH}$ & $1.13 \pm 0.12$ & $0.47 \pm 0.16$ & - & 6.49 & NS & NS \\
\hline Vos et al. [18] & $\begin{array}{l}\text { CAVH } \\
\text { CAVHD }\end{array}$ & SC: $1.05 \pm 0.19$ & - & - & $\begin{array}{l}9 \pm 3(\mathrm{CVVH}) \\
16 \pm 7(\mathrm{Qd} 1 \mathrm{~L} / \mathrm{h}) \\
30 \pm 7(\mathrm{Qd} 3 \mathrm{~L} / \mathrm{h})\end{array}$ & NS & NS \\
\hline Mueller et al. [2] & $\mathrm{CVVH}$ & 0.8 & $0.33 \pm 0.09$ & $95 \pm 13.8$ & 13.3 & NS & NS \\
\hline Hashimoto et al. [24] & CVHD & - & $0.38 \pm 0.13$ & $70.62 \pm 14.6$ & $18.74 \pm 1.2$ & NS & NS \\
\hline Fish et al. [23] & $\begin{array}{l}\text { CVVH } \\
\text { CVVHDF }\end{array}$ & $\begin{array}{l}1.21 \pm 0.11 \\
(\mathrm{CV} H) \\
1.28 \pm 0.17 \\
(\mathrm{CV} \text { HDF })\end{array}$ & $\begin{array}{l}0.36 \pm 0.1 \\
(\mathrm{CV} H) \\
0.37 \pm 0.13 \\
(\mathrm{CVVHDF})\end{array}$ & $\begin{array}{l}109 \pm 24 \\
(\mathrm{CVVH}) \\
120 \pm 32 \\
(\mathrm{CVVHDF})\end{array}$ & $\begin{array}{l}36 \pm 13 \\
(\mathrm{CWVH}) \\
57 \pm 28 \\
(\mathrm{CWVHDF})\end{array}$ & Yes & Yes \\
\hline Afshartous et al. [21] & CVVHD & - & 0.32 & - & $32.4 \pm 9.8^{*}$ & Yes & NS \\
\hline Boucher et al. [22] & $\mathrm{CVVH}$ & $1.01 \pm 0.12$ & $0.39 \pm 0.27$ & 191.5 & 54.5 & No & NS \\
\hline Wen et al. [19] & $\begin{array}{l}\text { CVHDF } \\
\text { CWHH }\end{array}$ & - & $\begin{array}{l}0.37 \pm 0.19 \text { (CVHDF) } \\
1.11 \\
(\mathrm{CVVH})\end{array}$ & - & $\begin{array}{l}1.9 \mathrm{~mL} / \mathrm{min} / \mathrm{kg} \\
(\mathrm{CVVHDF}) \\
2.8 \mathrm{~mL} / \mathrm{min} / \mathrm{kg}(\mathrm{CVVH})\end{array}$ & Yes & NS \\
\hline Breilh et al. [26] & $\mathrm{CVVH}$ & $0.52-0.80$ & 0.33 & 236.59 & 32.62 & Yes & NS \\
\hline
\end{tabular}

NS, data not stated

*Carbapenem CRRT clearance

\section{Basic pharmacokinetic parameters}

The pharmacokinetic parameters of interest were $\mathrm{Vd}$, and clearance where all studies reported $\mathrm{Vd}$, and 90\% reported total and CRRT clearances. Only 27\% mentioned protein binding or serum albumin levels (Fig. 2c).

\section{Specific CRRT clearance parameters}

Across 10 selected studies, five of them studied patients undergoing $\mathrm{CVVH}$, where most of them were treated with either polysulfone or AN-69 hemofilters. CVVHD and CVVHDF were utilized in 3 and 2 studies, respectively. Dilution methods were reported in $75 \%$ of the studies. Pre-dilution mode was mentioned at $62.5 \%$ of both CVVH and CVVHDF modalities. Blood flow rate and hematocrit, the parameters for calculating the correction factor in pre-dilution $\mathrm{CVVH}$, were revealed and accounted for $83.3 \%$ and $16.6 \%$, respectively. Of note, $72 \%$ of the studies reported SC or SA (Fig. 2d).

\section{The optimal dosage regimens of imipenem}

The PTAs of imipenem dosing regimens for Pseudomonas aeruginosa infections with $\mathrm{MIC} \leq 2 \mathrm{mg} / \mathrm{L}$ in pre-dilution CVVH and CVVHD modalities with 25 and $35 \mathrm{~mL} / \mathrm{kg} / \mathrm{h}$ effluent rates are shown in Tables 2 and 3. A regimen of $500 \mathrm{mg}$ every $8 \mathrm{~h}$ is the optimal dose to achieve pharmacodynamic targets of $40 \% \mathrm{fT}>\mathrm{MIC}$ for both CVVH and CVVHD at the effluent rate of 25 and $35 \mathrm{~mL} / \mathrm{kg} / \mathrm{h}$. However, with more aggressive target of $40 \% \mathrm{fT}>4 \mathrm{MIC}$, regardless of the effluent flow rates or modality, the optimal dose is $750 \mathrm{mg}$ every $6 \mathrm{~h}$. For a target of $100 \% \mathrm{fT}>\mathrm{MIC}$, the optimal regimens for $\mathrm{CVVH}$ include $2500 \mathrm{mg}$ every $8 \mathrm{~h}$ and $2000 \mathrm{mg}$ every $6 \mathrm{~h}$ for the effluent flow rates of 25 and $35 \mathrm{ml} / \mathrm{min} / \mathrm{kg}$, respectively. All necessary variables for dosing the drug including pharmacokinetic parameters, CRRT setting, and patient characteristics are described in Table 4. The recommendations of imipenem dosing regimens for treating Pseudomonas aeruginosa infections with various pharmacodynamic targets in critically ill patients undergoing CRRT from the simulations are summarized in Table 5. Figure 3 demonstrates the PTA results of meropenem dosing regimens at different MICs in pre-dilution CVVH with $25 \mathrm{~mL} / \mathrm{kg} / \mathrm{h}$ effluent rates for treatment of Pseudomonas aeruginosa infection in virtual patients for the first $48 \mathrm{~h}$.

\section{Discussions}

In our study, we conducted a systematic review of pharmacokinetic studies of imipenem in critically ill patients receiving CRRT. Our review indicated that the current 


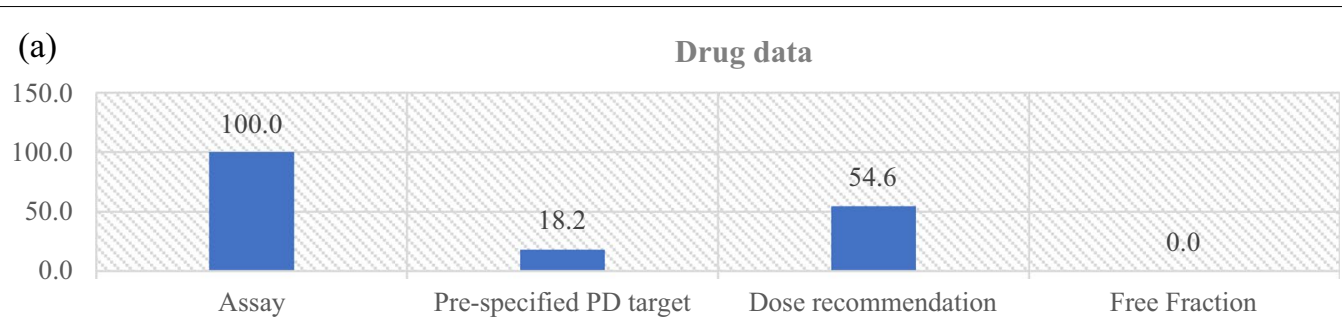

(b) Patient demographics

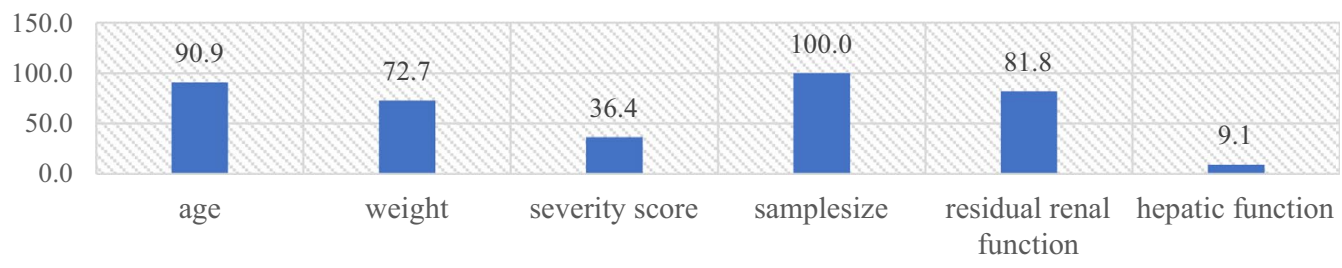

(c) Basic pharmacokinetics
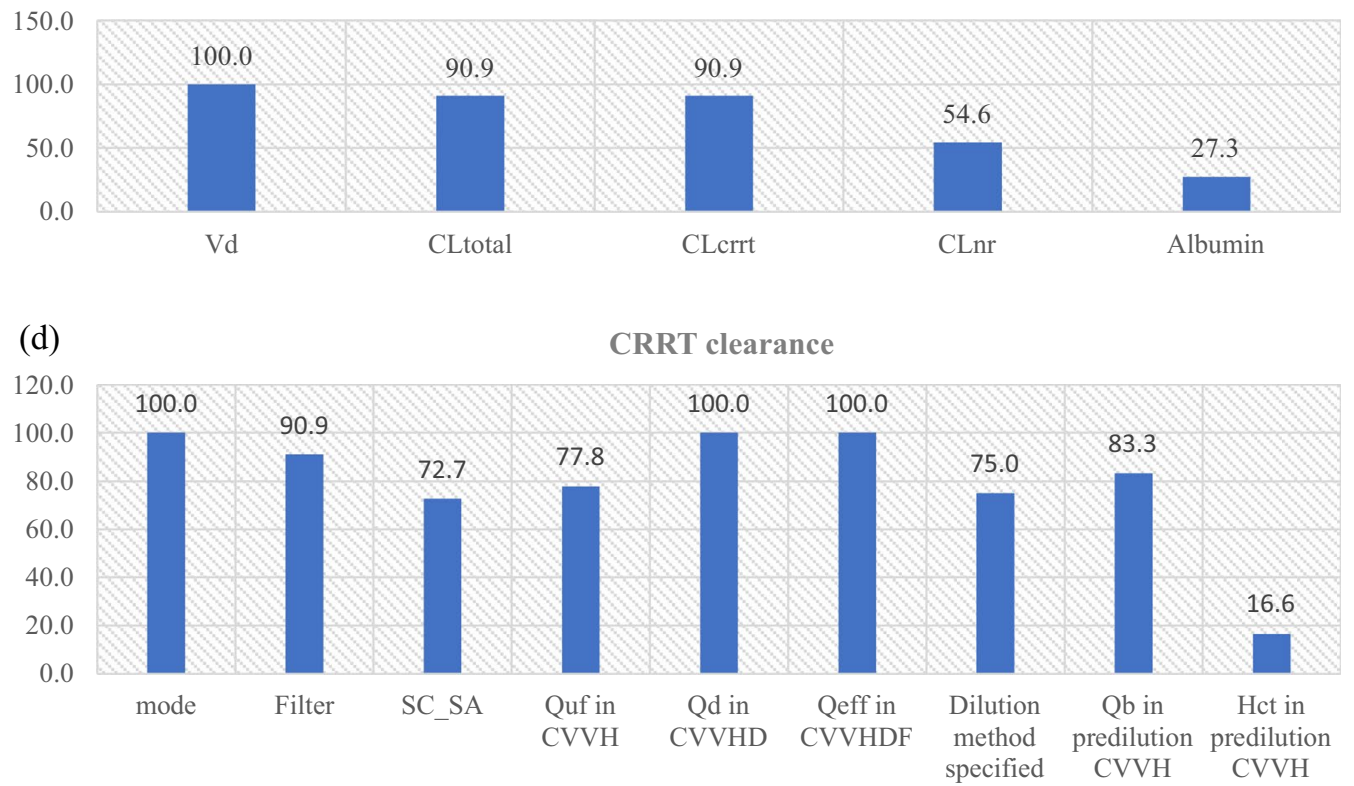

Fig. 2 Data on characteristics obtained from literature analysis

literature does not provide sufficient information for drug dosing in patients with CRRT. CRRT operational characteristics and pharmacokinetic parameters as well as the pharmacodynamic target should be considered to design dosage regimen in this population.

\section{Effect of CRRT modality and drug clearance}

The studies evaluated for this review were mostly done as continuous treatments $(>24 \mathrm{~h})$. However, the variability in treatment modalities and operational characteristics (blood, dialysate, effluent flow rates, pre- vs post-dilution, etc.) were significant. With all the variability, overall key pharmacokinetic parameters are comparable across all modalities (Vd: $0.29-0.47 \mathrm{~L} / \mathrm{kg}$ for CAVH, 0.33-0.39 L/kg for CVVH, and $0.32-0.38 \mathrm{~L} /$ $\mathrm{kg}$ for CVVHDF) (Table 1) [2, 16-26].

Imipenem is a moderately hydrophilic drug with $\mathrm{Vd}$ of $0.23-0.35 \mathrm{~L} / \mathrm{kg}$ [2] and low protein binding ( 20\%) [3]. Because of these characteristics, it can be removed efficiently by CRRT with consequent need for a careful dosage adjustment [29]. Theoretically, diffusive technique is considered to be a better modality for solute 
Table 2 PTA of all recommended imipenem dosing regimens for Pseudomonas aeruginosa infections in pre-dilution CVH modality with 25 and $35 \mathrm{~mL} / \mathrm{kg} / \mathrm{h}$ effluent rates

\begin{tabular}{|c|c|c|c|c|c|c|}
\hline \multirow[t]{3}{*}{ Dosage regimens } & \multicolumn{6}{|c|}{ Probability of target attainment over $48 \mathrm{~h}, \mathrm{MIC}$ of $2 \mathrm{mg} / \mathrm{L}$} \\
\hline & \multicolumn{3}{|c|}{ Effluent rates $25 \mathrm{~mL} / \mathrm{kg} / \mathrm{h}$} & \multicolumn{3}{|c|}{ Effluent rates $35 \mathrm{~mL} / \mathrm{kg} / \mathrm{h}$} \\
\hline & $40 \% \mathrm{fT}>\mathrm{MIC}$ & $40 \% \mathrm{fT}>4 \mathrm{MIC}$ & $100 \% \mathrm{fT}>\mathrm{MIC}$ & $40 \% \mathrm{fT}>\mathrm{MIC}$ & $40 \% \mathrm{fT}>4 \mathrm{MIC}$ & $100 \% \mathrm{fT}>\mathrm{MIC}$ \\
\hline $500 \mathrm{mg} \mathrm{q} 8 \mathrm{~h}^{*}$ & 0.9994 & 0.1708 & 0.0290 & 0.9998 & 0.1076 & 0.0172 \\
\hline $750 \mathrm{mg} \mathrm{q} 12 \mathrm{~h}^{*}$ & 0.9850 & 0.1044 & 0.0142 & 0.9752 & 0.0598 & 0.0062 \\
\hline $500 \mathrm{mg} \mathrm{q} 6 \mathrm{~h}^{*}$ & 1 & 0.5594 & 0.1288 & 1 & 0.4654 & 0.1074 \\
\hline 1000 mg LD 500 mg q $8 h^{*}$ & 1 & 0.3090 & 0.2288 & 0.9996 & 0.2280 & 0.1706 \\
\hline 1000 mg LD 500 mg q 6 h & 1 & 0.6942 & 0.5554 & 1 & 0.6088 & 0.4992 \\
\hline $750 \mathrm{mg} \mathrm{q} 6 \mathrm{~h}$ & 1 & 0.9396 & 0.4388 & 1 & 0.9208 & 0.4122 \\
\hline $1000 \mathrm{mg} \mathrm{q} 8 \mathrm{~h}$ & 1 & 0.9280 & 0.4702 & 1 & 0.8878 & 0.4174 \\
\hline 2000 mg LD 1000 mg q 8 h & 1 & 0.9700 & 0.7122 & 1 & 0.9560 & 0.6818 \\
\hline 2000 mg q $12 \mathrm{~h}$ & 0.9996 & 0.9426 & 0.4750 & 0.9984 & 0.9082 & 0.3946 \\
\hline 2500 mg q $8 \mathrm{~h}$ & 1 & 1 & 0.9108 & 1 & 0.9996 & 0.8938 \\
\hline 2000 mg q 6 h & 1 & 1 & 0.9558 & 1 & 1 & 0.9536 \\
\hline $3000 \mathrm{mg} \mathrm{q} 8 \mathrm{~h}$ & 1 & 1 & 0.9430 & 1 & 1 & 0.9204 \\
\hline $16,000 \mathrm{mg} \mathrm{q} 12 \mathrm{~h}$ & 1 & 0.9998 & 0.9002 & 1 & 0.9996 & 0.8772 \\
\hline $22,000 \mathrm{mg} \mathrm{q} 12 \mathrm{~h}$ & 1 & 1 & 0.9334 & 1 & 1 & 0.9010 \\
\hline
\end{tabular}

PTA probability of target attainment, $C V V H$ continuous venovenous hemofiltration, $L D$ loading dose *Literature based regimens

Table 3 PTA of all recommended imipenem dosing regimens for Pseudomonas aeruginosa infections in CVVHD modality with 25 and $35 \mathrm{~mL} / \mathrm{kg} / \mathrm{h}$ effluent rates

\begin{tabular}{|c|c|c|c|c|c|c|}
\hline \multirow[t]{3}{*}{ Dosage regimens } & \multicolumn{6}{|c|}{ Probability of target attainment over $48 \mathrm{~h}, \mathrm{MIC}$ of $2 \mathrm{mg} / \mathrm{L}$} \\
\hline & \multicolumn{3}{|c|}{ Effluent rates $25 \mathrm{~mL} / \mathrm{kg} / \mathrm{h}$} & \multicolumn{3}{|c|}{ Effluent rates $35 \mathrm{~mL} / \mathrm{kg} / \mathrm{h}$} \\
\hline & $40 \% \mathrm{fT}>\mathrm{MIC}$ & $40 \% \mathrm{fT}>4 \mathrm{MIC}$ & $100 \% \mathrm{fT}>\mathrm{MIC}$ & $40 \% \mathrm{fT}>\mathrm{MIC}$ & $40 \% \mathrm{fT}>4 \mathrm{MIC}$ & $100 \% \mathrm{fT}>\mathrm{MIC}$ \\
\hline $500 \mathrm{mg} \mathrm{q} 8 \mathrm{~h}^{*}$ & 1 & 0.1970 & 0.0408 & 0.9992 & 0.1318 & 0.0196 \\
\hline $750 \mathrm{mg} \mathrm{q} 12 \mathrm{~h}^{*}$ & 0.9864 & 0.1340 & 0.0238 & 0.9734 & 0.0674 & 0.0096 \\
\hline $500 \mathrm{mg} \mathrm{q} 6 \mathrm{~h}^{*}$ & 1 & 0.5812 & 0.1484 & 0.9998 & 0.4710 & 0.1182 \\
\hline 1000 mg LD 500 mg q 8 h* & 1 & 0.3434 & 0.2676 & 0.9994 & 0.2490 & 0.1910 \\
\hline 1000 mg LD 500 mg q 6 h* & 1 & 0.7230 & 0.5804 & 1 & 0.6152 & 0.4968 \\
\hline 750 mg q 6 h & 1 & 0.9388 & 0.4668 & 1 & 0.9052 & 0.4234 \\
\hline 1000 mg q $8 \mathrm{~h}$ & 1 & 0.9214 & 0.4926 & 1 & 0.8700 & 0.4112 \\
\hline 2000 mg q $12 \mathrm{~h}$ & 0.9988 & 0.9408 & 0.4906 & 0.9976 & 0.9000 & 0.4010 \\
\hline $1500 \mathrm{mg} \mathrm{q} 8 \mathrm{~h}$ & 1 & 0.9966 & 0.7700 & 1 & 0.9948 & 0.7128 \\
\hline $1500 \mathrm{mg} \mathrm{q} 6 \mathrm{~h}$ & 1 & 1 & 0.9016 & 1 & 0.9992 & 0.8826 \\
\hline $2000 \mathrm{mg}$ LD then $1500 \mathrm{mg} \mathrm{q} 6 \mathrm{~h}$ & 1 & 1 & 0.9500 & 1 & 0.9996 & 0.9402 \\
\hline 2500 mg q $8 \mathrm{~h}$ & 1 & 0.9998 & 0.9254 & 1 & 1 & 0.8872 \\
\hline $3000 \mathrm{mg}$ LD then $2500 \mathrm{mg} \mathrm{q} 8 \mathrm{~h}$ & 1 & 0.9998 & 0.9322 & 1 & 1 & 0.9138 \\
\hline $16,000 \mathrm{mg} \mathrm{q} 12 \mathrm{~h}$ & 1 & 0.9998 & 0.9036 & 1 & 0.9998 & 0.8862 \\
\hline $22,000 \mathrm{mg} \mathrm{q} 12 \mathrm{~h}$ & 1 & 0.9998 & 0.9330 & 1 & 0.9998 & 0.9058 \\
\hline
\end{tabular}

PTA probability of target attainment, CVVHD continuous venovenous hemodialysis, LD loading dose *Literature based regimens 
Table 4 Virtual patient characteristics and key pharmacokinetic parameters from simulation

\begin{tabular}{ll}
\hline Parameters & $\begin{array}{l}\text { Simulation-based values } \\
\text { (mean } \pm \text { SD (range limits)) }\end{array}$ \\
\hline Weight $(\mathrm{kg})$ & $86.6 \pm 29.2(40-\infty), \mathrm{N}=100$ \\
$\mathrm{~V}_{\mathrm{d}}(\mathrm{L} / \mathrm{kg})$ & $0.34 \pm 0.11(0.15-0.63), \mathrm{N}=33$ \\
$\mathrm{CL}_{\mathrm{NR}}(\mathrm{mL} / \mathrm{min})$ & $103.82 \pm 28.95(52.51-168.0), \mathrm{N}=31$ \\
Residual renal clearance $(\mathrm{mL} / \mathrm{min})$ & 0 \\
$\mathrm{SC}$ & $1.05 \pm 0.17(0.8-1.34), \mathrm{N}=32$ \\
$\mathrm{SA}$ & $0.77 \pm 0.33(0.37-1.52), \mathrm{N}=54$ \\
$\mathrm{Qb}(\mathrm{mL} / \mathrm{min})$ & 200 \\
$\mathrm{Hct}(\%)$ & 30 \\
Qf or Qd (mL/kg/h) & 25 and 35 \\
Free fraction & $0.8 \pm 0.16$ \\
Pharmacodynamic target & $40 \% \mathrm{fT}>\mathrm{MIC}$ \\
& $40 \% \mathrm{fT}>4 \mathrm{MIC}$ \\
& $100 \% \mathrm{fT}>\mathrm{MIC}$ \\
\hline
\end{tabular}

$S D$ standard deviation, $\mathrm{kg}$ kilogram, $N$ number of patients, $L$ liter, $m L$ milliliter, min minute, $S C$ seiving coefficient, $S D$ saturation coefficient, $Q b$ blood flow rate, Hct hematocrit, Qf ultrafiltration rate, $Q d$ dialysate flow rate, $f T / M I C$ free drug level above 4 times of the minimum inhibitory concentration

Table 5 Recommendations of imipenem dosing regimens for treating Pseudomonas aeruginosa infections with various PD target in critically ill patients undergoing CRRT

\begin{tabular}{llll}
\hline PD target & $\begin{array}{l}\text { Effluent rates } \\
\text { (mL/kg/h) }\end{array}$ & $\begin{array}{l}\text { CVVH (pre- } \\
\text { hemofilter } \\
\text { dilution) }\end{array}$ & CVVHD \\
\hline $40 \% \mathrm{fT}>$ MIC & $25 \mathrm{~mL} / \mathrm{kg} / \mathrm{h}$ & $500 \mathrm{mg} \mathrm{q} 8 \mathrm{~h}$ or & $500 \mathrm{mg} \mathrm{q} 8 \mathrm{~h}$ \\
& $35 \mathrm{~mL} / \mathrm{kg} / \mathrm{h}$ & $750 \mathrm{mg} \mathrm{q} 12 \mathrm{~h}$ & $750 \mathrm{mg} \mathrm{q} 12 \mathrm{~h}$ \\
$40 \% \mathrm{fT}>4 \mathrm{MIC}$ & $25 \mathrm{~mL} / \mathrm{kg} / \mathrm{h}$ & $750 \mathrm{mg} \mathrm{q} 6 \mathrm{~h}$ & $750 \mathrm{mg} \mathrm{q} 6 \mathrm{~h}$ \\
& $35 \mathrm{~mL} / \mathrm{kg} / \mathrm{h}$ & & \\
$100 \% \mathrm{fT}>$ MIC & $25 \mathrm{~mL} / \mathrm{kg} / \mathrm{h}$ & $2500 \mathrm{mg} \mathrm{q} 8 \mathrm{~h}$ & $1500 \mathrm{mg} \mathrm{q} 6 \mathrm{~h}$ \\
& $35 \mathrm{~mL} / \mathrm{kg} / \mathrm{h}$ & $2000 \mathrm{mg} \mathrm{q} 6 \mathrm{~h}$ & $2000 \mathrm{mg} \mathrm{LD} \mathrm{then}$ \\
& & & $1500 \mathrm{mg} \mathrm{q} 6 \mathrm{~h}$ \\
\hline
\end{tabular}

$\mathrm{CVVH}$ continuous venovenous hemofiltration, $\mathrm{CVVHD}$ continuous venovenous hemodialysis, $L D$ loading dose

clearance, than of the convection technique. Thus, one can assume that the clearance of imipenem in CVVHDF should be greater than CVVH. However, several pharmacokinetic studies published over the past years have shown the opposite. Giles et al. reported meropenem clearance (similar PK characteristics to imipenem, Vd 0.35 L/kg, MW 383 Da [30]) between CVVH and CVVHDF with the comparable intensity to be 3.9 $\mathrm{L} / \mathrm{h}$ and $4.7 \mathrm{~L} / \mathrm{h}$, respectively [31]. Similar results were reported in simulation studies which they suggested that modality had a minimal impact on drug clearance and drug dosing recommendation [32, 33]. In our review, Fish reported $\mathrm{CL}_{\mathrm{CVVHDF}}$ was $57 \pm 28 \mathrm{ml} / \mathrm{min}$, while the $\mathrm{CL}_{\mathrm{CVVH}}$ was only $36 \pm 13 \mathrm{ml} / \mathrm{min}$. Though it seemed that CVVHDF yielded a higher imipenem clearance, the replacement fluid rate from CVVHDF was $35.5 \mathrm{~mL} / \mathrm{min}$, while it was only $18.8 \mathrm{~mL} / \mathrm{min}$ for CVVH, suggesting that imipenem clearance between CRRT modalities cannot be determined solely based on the mode, rather the replacement fluid rate should also be considered. Vos et al. reported imipenem clearance to be $16 \pm 7(\mathrm{Qd} 1 \mathrm{~L} / \mathrm{h})$ and $30 \pm 7(\mathrm{Qd} 3 \mathrm{~L} / \mathrm{h})$ in patients receiving CAVHD [18]. Similar findings were also reported in simulation studies in which rates of replacement fluid impact the drug concentration and pharmacodynamic target attainment [32, 33]. In our review, all studies reported CRRT modality; however, only $77 \%$ reported effluent flow rate for $\mathrm{CVVH}$. This discrepancy can explain why the clearance and ultimately dosing recommendations from each study were different.

\section{Effect of pharmacokinetic parameters}

The pharmacokinetic changes of hydrophilic drug in critically ill patients such as increased Vd due to volume overload and decreased protein binding due to catabolic state can drastically lower drug concentration [34]. Based on our review, the imipenem volume of distribution from critically ill AKI patients approximated 0.29 to $1.1 \mathrm{~L} / \mathrm{kg}$. This value is slightly higher than reported in normal population $(0.2-0.3 \mathrm{~L} / \mathrm{kg})$. As $\mathrm{Cl}=\mathrm{k}_{\mathrm{e}} \mathrm{x} \mathrm{Vd}$, the variation in $\mathrm{Vd}$ would affect drug clearance and the probability of pharmacodynamic target attainment.

As most patients in the reviewed studies were anuric, non-renal clearance was regarded as all clearance that was not due to the effect of hemofilter. In the studies that specifically examined non-renal clearance, some was calculated as the difference between total body clearance and clearance due to hemofilter $\left(\mathrm{CL}_{\mathrm{NR}}=\mathrm{CL}_{\mathrm{TOT}}-\mathrm{CL}_{\mathrm{CRRT}}\right.$ ). Based on this equation, the non-renal equation is comprised of hepatic clearance and the remaining clearance that came from urine production. Therefore, examining residual renal function in each study is important to determine the dosing recommendation from the pharmacokinetic studies. However, only $80 \%$ of the studies reviewed elaborated the residual renal function. In our review, non-renal clearance averages $103.82 \mathrm{~mL} /$ min. Mueller et al. described the significant of non-renal clearance for imipenem by comparing AKI and CKD patients receiving $\mathrm{CVVH}$ and found that non-renal clearance in critically ill AKI patients was greater than CKD (95 vs $51 \mathrm{~mL} / \mathrm{min}$, respectively), resulting in the higher dose recommended in the AKI group [2]. This shows the significant of examining non-renal clearance in clinical studies. Unfortunately, only $50 \%$ reported $\mathrm{CL}_{\mathrm{NR}}$ in the studies reviewed. 


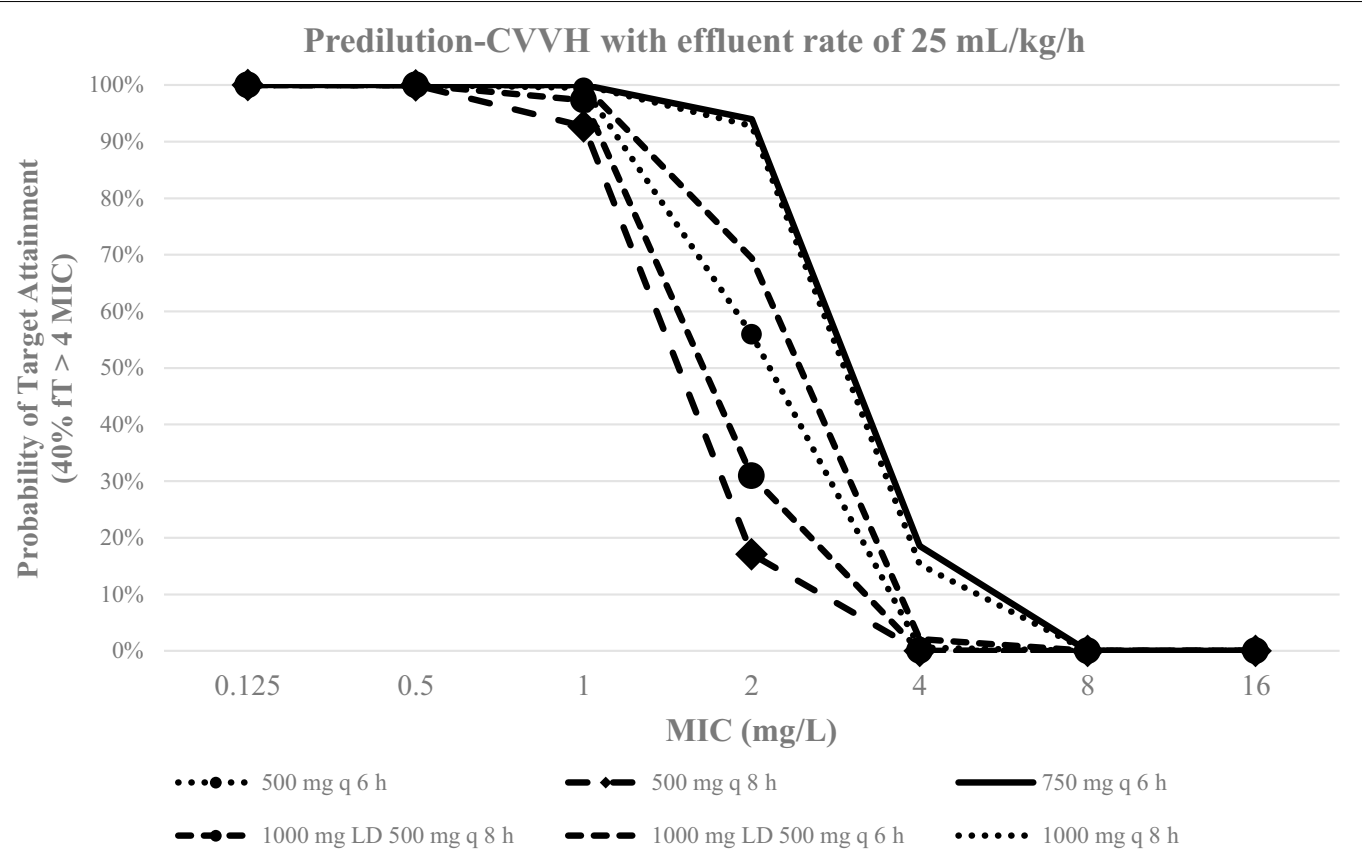

Fig. 3 PTA results of imipenem dosing regimens at different MICs in pre-dilution CVVH with $25 \mathrm{~mL} / \mathrm{kg} / \mathrm{h}$ effluent rates for treatment of Pseudomonas aeruginosa infection in virtual patients for the first $48 \mathrm{~h}$

Additionally, volume overload in ICU patients has been shown to be associated with hypoalbuminemia and could increase free drug concentrations that would be removed by CRRT, the liver, and the kidney [34]. Given these reasons described, the loading dose concept is crucial to attain the PTA target in these situations. Therefore, knowing the serum albumin for the patients studied could be beneficial in determining drug dosing. However, less than $30 \%$ reported serum albumin in our review.

\section{Effect of pharmacodynamic parameters}

In this systematic review, wide variability of dosing recommendation was observed. Doses ranging from $500 \mathrm{mg}$ every $24 \mathrm{~h}$ to $1,000 \mathrm{mg}$ every $24 \mathrm{~h}$ was suggested. The variety of dosing recommendations can be explained by the difference in pharmacodynamic targets. In an animal study, the bacteriostatic effect was demonstrated when $\mathrm{fT}>\mathrm{MIC}$ greater than $20 \%$. When the $\mathrm{fT}>\mathrm{MIC}$ greater than $40 \%$, the bactericidal effect can be observed [35]. Nonetheless, Tam et al. suggested that achieving higher target as fourfold MIC was associated with maximum bactericidal activity of $\beta$-lactams [36]. Fish et al. recommended imipenem dosing regimen of $500 \mathrm{mg}$ every $6 \mathrm{~h}$ for the PD target of $50-80 \% \mathrm{fT}>\mathrm{MIC}$ (MIC of $\leq 4 \mathrm{mcg} /$ $\mathrm{ml}$ in patients undergoing CVVH and CVVHDF [23]. While Afshartous et al. aimed for more aggressive target of $40 \% \mathrm{fT}>4 \mathrm{MIC}$, the dose of $500 \mathrm{mg}$ every $6-8 \mathrm{~h}$ failed to achieve the target and was not recommended [21].
This showed the significance of including pharmacodynamic target in the study as the impact on dosing recommendation is immense. Unfortunately, only $18 \%$ of the studies reviewed reported the pharmacodynamic target to support their dosing recommendation.

\section{Effect of patient demographic}

The demographic of the studied patients should be mentioned for the generalizability of the study. Extracellular volume overload may increase the apparent volume of distribution of highly water-soluble drugs; thus, usual doses may result in low plasma levels in volume overloaded patients and may require a loading dose or higher maintenance dose. Non-renal clearance as mentioned above also contributes significantly to total drug clearance and therefore should be described. Further, residual renal function of the patients studied will impact the clearance and ultimately dosing recommendation. $\mathrm{Li}$ et al. suggested that with the same pharmacodynamic target, patients with oliguria were less likely to achieve pharmacodynamic target attainment [15]. Thus, to be able to apply the results to the specific patients, these patient demographics must be demonstrated. In our review, about $80 \%$ reported residual renal function with only $30 \%$ reported disease severity. 


\section{The optimal dosage regimens of imipenem}

Our simulation suggested that imipenem dosing regimen of $750 \mathrm{mg}$ every $6 \mathrm{~h}$ is able to achieve a PD target of $40 \% \mathrm{fT}>4 \mathrm{MIC}$ (MIC of $2 \mathrm{mg} / \mathrm{L}$ ), regardless of effluent rates and modalities. The aggressive pharmacodynamic target was chosen in our simulation, particularly for the treatment of severe infection which are common in critically ill patients. Our dosing recommendations are higher than the previous study by Fish et al., which they recommended at lower PD target of $40 \% \mathrm{fT}>\mathrm{MIC}$ (MIC of $2 \mathrm{mg} / \mathrm{L}$ ). Both Fish et al. and our simulations showed also that the effect of different CRRT modality was minimal. Conversely, Wen et al. recommended that the doses of $500 \mathrm{mg}$ every $6 \mathrm{~h}$ and $1 \mathrm{~g}$ every $8 \mathrm{~h}$ could not achieve the therapeutic target of $40 \% \mathrm{fT}>4 \mathrm{MIC}$ (MIC of $16 \mathrm{mg} / \mathrm{L}$ ) and may cause therapeutic failure. The difference in dosing recommendation can be explained by the different in PD targets and several patients in Wen's study had significant residual renal function, both of which resulted in the higher dosing requirement. When applying more aggressive target of $100 \% \mathrm{fT}>\mathrm{MIC}$, our simulations showed the regimen of $2,500 \mathrm{mg}$ every $8 \mathrm{~h}$ is recommended for CVVH at the effluent rate of $25 \mathrm{~mL} / \mathrm{kg} / \mathrm{h}$. Though this dose is able to meet PD target, it is exceeding the maximum dosing recommendation for normal renal function $(4 \mathrm{~g} /$ day). Despite the negligible neurological side effect of imipenem vs other carbapenems [7], imipenem has been associated with several reports of causing seizures and central nervous system toxicity in circumstance that the therapeutic drug level is elevated and in patients with predisposing factors [8]. Therefore, the safety for the aforementioned doses cannot be guaranteed. Applying this high dose in clinical practice cannot be recommended.

\section{Limitation}

The clinicians using the results from our simulation should be aware that we did not account for residual renal function to our dosing recommendation. The articles were included if they were published in English. Lastly, our recommendations should be utilized for the patients who share similar clinical characteristics. Clinical validation of our recommendations is suggested.

\section{Conclusions}

None of the current published studies reported both necessary pharmacokinetic parameters and operational characteristics of CRRT. CRRT dose and modality have minimal impact on drug dosing requirement to achieve PD target. On the other hand, we found that the aggressiveness of PD target is the key contributor for imipenem dosing regimens. Our study suggests that a regimen of $750 \mathrm{mg}$ every $6 \mathrm{~h}$ is the optimal dose to achieve pharmacodynamic targets of $40 \% \mathrm{fT}>4 \mathrm{MIC}$ for both CVVH and CVVHD at the effluent rate of 25 and $35 \mathrm{~mL} / \mathrm{kg} / \mathrm{h}$. Further exploring clinical outcomes and validation are recommended.

\begin{abstract}
Abbreviations
AKI: Acute kidney injury; APACHE: Acute Physiology and Chronic Health Evaluation; $\mathrm{CL}_{\mathrm{NR}}$ : Non-renal clearance; $\mathrm{CRRT}$ : Continuous renal replacement therapy; CVVH: Continuous venovenous hemofiltration; CVVHD: Continuous venovenous hemodialysis; ECMO: Extracorporeal Membrane Oxygenation; $\mathrm{fT}>\mathrm{MIC}$. The cumulative percentage of a $48 \mathrm{~h}$ period with 1 times MIC; fT > $4 \mathrm{MIC}$ : The cumulative percentage of a $48 \mathrm{~h}$ period with 4 times MIC; $\mathrm{g}$ : $\mathrm{Gram} ; \mathrm{g} / \mathrm{mol}$ : Gram/mol; h: Hour; Hct: Hematocrit; IHD: Intermittent hemodialysis; KDIGO: Kidney Disease: Improving Global Outcomes; kg: Kilogram; L: Liter; LD: Loading dose; MeSH: Medical Subject Headings; mg: Milligram; MIC: Minimum inhibitory concentration; mL: Milliliter; N: Number; POP-PK: Population pharmacokinetics study; PTA: Probability of target attainment; Q: Every; Qb: Blood flow rate; Qd: Dialysate flow rate; Qrep: Replacement flow rate; Qf: Ultrafiltrate rate; $r^{2}$ : Population-specific correlation; SA: Saturation coefficient; SC: Sieving coefficient; SD: Standard deviation; SLED: Sustained low-efficiency dialysis; SOFA: The Sequential Organ Failure Assessment; Vd: Volume of distribution.
\end{abstract}

\section{Acknowledgements}

Not applicable.

\section{Authors' contributions}

TC and WC equally contributed to the conception and design of the research; TC, WC, PK, NK, PT, AP, and SP equally contributed to the acquisition, analysis, and interpretation of the data; TC, DR, and WC drafted the manuscript. All authors critically revised the manuscript, read, and approved the final manuscript.

\section{Funding}

This study was supported by the funding from the Siam University. The funding source had no role in the study design, the collection, analysis, and interpretation of data, the writing of the article, and the decision to submit it for publication.

\section{Availability of data and materials}

The datasets used and/or analyzed during the current study are available from the corresponding author on reasonable request.

\section{Declarations}

Ethic approval and consent to participate

Not applicable.

\section{Consent for publication}

Not applicable.

\section{Competing interests}

All authors declare that they have no competing interests.

\section{Author details}

${ }^{1}$ Department of Clinical and Administrative Pharmacy Sciences, Howard University College of Pharmacy, Washington, DC, USA. ${ }^{2}$ Faculty of Pharmacy, Siam University, Bangkok, Thailand. ${ }^{3}$ Division of Pharmacy Practice, Department of Pharmaceutical Care, School of Pharmaceutical Sciences, University of Phayao, Phayao, Thailand. ${ }^{4}$ Department of Clinical Pharmacy, Faculty of Pharmaceutical Sciences, Prince of Songkla University, Songkhla, Thailand. ${ }^{5}$ Division of Nephrology, Department of Medicine, Faculty of Medicine, Chulalongkorn University, King Chulalongkorn Memorial Hospital, Bangkok, Thailand. ${ }^{6}$ Excellence Center for Critical Care Nephrology, King Chulalongkorn Memorial Hospital, Bangkok, Thailand. ${ }^{7}$ Critical Care Nephrology Research Unit, Faculty of Medicine, Chulalongkorn University, Bangkok, Thailand. ${ }^{8}$ Academic of Science, Royal Society of Thailand, Bangkok, Thailand. ${ }^{9}$ Tropical Medicine Cluster, Chulalongkorn University, Bangkok, Thailand. ${ }^{10}$ Department of Critical 
Care Medicine, Center for Critical Care Nephrology, The CRISMA Center, University of Pittsburgh School of Medicine, Pittsburgh, PA, USA.

\section{Received: 29 April 2021 Accepted: 16 October 2021}

Published online: 29 October 2021

\section{References}

1. Rogers JD, Meisinger MAL, Ferber F, Calendra GB, Demetriades JL, Bland JA. Pharmacokinetics of imipenem/ cilastatin in volunteers. Rev Infect Dis. 1985;7(Suppl 3):S435-46.

2. Mueller B, Scarim SK, Macias WL. Comparison of imipenem pharmacokinetics in patients with acute or chronic renal failure treated with continuous hemofiltration. Am J Kidney Dis. 1993;21(2):172-9.

3. Imipenem. IBM micromedex solutions. Ann Arbor: Truven Health Analytics, Inc.; 2021.

4. Metlay JP, Waterer GW, Long AC, et al. Diagnosis and treatment of adults with community-acquired pneumonia. An official clinical practice guideline of the American thoracic society and infectious diseases society of America. Am J Respir Crit Care Med. 2019;200(7):e45-67.

5. Rhodes A, Evans LE, Alhazzani W, et al. Surviving sepsis campaign: international guidelines for management of sepsis and septic shock: 2016. Intensive Care Med. 2017:43(3):304-77.

6. Stevens DL, Bisno AL, Chambers HF, et al. Practice guidelines for the diagnosis and management of skin and soft tissue infections: 2014 update by the infectious diseases society of America. Clin Infect Dis. 2014;59(2):147-59.

7. Cannon JP, Lee TA, Clark NM, Setlak P, Grim SA. The risk of seizures among the carbapenems: a meta-analysis. J Antimicrob Chemother. 2014;69(8):2043-55.

8. Sutter R, Rüegg S, Tschudin-Sutter S. Seizures as adverse events of antibiotic drugs: a systematic review. Neurology. 2015;85(15):1332-41.

9. Seyler L, Cotton F, Taccone FS, et al. Recommended $\beta$-lactam regimens are inadequate in septic patients treated with continuous renal replacement therapy. Crit Care. 2011;15(3):R137.

10. Drusano GL. Antimicrobial pharmacodynamics: critical interactions of "bug and drug." Nat Rev Microbiol. 2004;2(4):289-300.

11. Chaijamorn W, Charoensareerat T, Srisawat N, Pattharachayakul S, Boonpeng A. Cefepime dosing regimens in critically ill patients receiving continuous renal replacement therapy: a Monte Carlo simulation study. J Intensive Care. 2018;6:61.

12. Kidney Disease: Improving Global, Outcomes (KDIGO) Acute Kidney Injury Work Group. KDIGO clinical practice guideline for acute kidney injury. Kidney Int. 2012;2(Suppl):1-138.

13. Chaijamorn W, Jitsurong A, Wiwattanawongsa K, Wanakamanee U, Dandecha P. Vancomycin clearance during continuous venovenous haemofiltration in critically ill patients. Int J Antimicrob Agents. 2011;38(2):152-6.

14. Li AM, Gomersall CD, Choi G, Tian Q, Joynt GM, Lipman J. A systematic review of antibiotic dosing regimens for septic patients receiving continuous renal replacement therapy: do current studies supply sufficient data? J Antimicrob Chemother. 2009;64(5):929-37.

15. Li S, Xie F. Population pharmacokinetics and simulations of imipenem in critically ill patients undergoing continuous renal replacement therapy. Int J Antimicrob Agents. 2019;53(1):98-105.

16. Przechera M, Bengel D, Risler T. Pharmacokinetics of imipenem/cilastatin during continuous arteriovenous hemofiltration. Contrib Nephrol. 1991;93:131-4.

17. Tegeder I, Bremer F, Oelkers R, et al. Pharmacokinetics of imipenemcilastatin in critically ill patients undergoing continuous venovenous hemofiltration. Antimicrob Agents Chemother. 1997:41(12):2640-5.

18. Vos MC, Vincent HH, Yzerman EP. Clearance of imipenem/cilastatin in acute renal failure patients treated by continuous hemodiafiltration (CAVHD). Intensive Care Med. 1992;18(5):282-5.
19. Wen A, Li Z, Yu J, et al. Clinical validation of therapeutic drug monitoring of imipenem in spent effluent in critically ill patients receiving continuous renal replacement therapy: a pilot study. PLOS ONE. 2016;11(4):e0153927.

20. Keller E, Fecht H, Böhler J, Schollmeyer P. Single-dose kinetics of imipenem/cilastatin during continuous arteriovenous haemofiltration in intensive care patients. Nephrol Dial Transplant. 1989;4(7):640-5.

21. Afshartous D, Bauer SR, Connor MJ, et al. Pharmacokinetics and pharmacodynamics of imipenem and meropenem in critically ill patients treated with continuous venovenous hemodialysis. Am J Kidney Dis. 2014;63(1):170-1.

22. Boucher BA, Hudson JQ, Hill DM, et al. Pharmacokinetics of imipenem/cilastatin burn intensive care unit patients undergoing highdose continuous venovenous hemofiltration. Pharmacotherapy. 2016;36(12):1229-37.

23. Fish DN, Teitelbaum I, Abraham E. Pharmacokinetics and pharmacodynamics of imipenem during continuous renal replacement therapy in critically ill patients. Antimicrob Agents Chemother. 2005;49(6):2421-8.

24. Hashimoto S, Honda M, Yamaguchi M, Sekimoto M, Tanaka Y. Pharmacokinetics of imipenem and cilastatin during continuous venovenous hemodialysis in patients who are critically ill. ASAIO J. 1997:43(1):84-8.

25. Breilh D, Honore PM, De Bels D, et al. Pharmacokinetics and pharmacodynamics of anti-infective agents during continuous veno-venous hemofiltration in critically ill patients: lessons learned from an ancillary study of the IVOIRE trial. J Transl Int Med. 2019;7(4):155-69.

26. Legrand M, Darmon M, Joannidis M, Payen D. Management of renal replacement therapy in ICU patients: an international survey. Intensive Care Med. 2013;39(1):101-8.

27. Daniel J, Schaffer J, Kim M-J, Shaw D, Thongteeraparp A, Supawan P. Number of replications required in Monte Carlo simulation studies: a synthesis of four studies. J Mod Appl Stat Methods. 2011;10:5-6.

28. Clinical Laboratory Standards Institute. Performance standards for antimicrobial susceptibility testing. 30th ed. Wayne: CLSI; 2020.

29. Pea F, Viale P, Pavan F, Furlanut M. Pharmacokinetic considerations for antimicrobial therapy in patients receiving renal replacement therapy. Clin Pharmacokinet. 2007;46(12):997-1038. https://doi.org/10.2165/ 00003088-200746120-00003.

30. Pistolesi V, Morabito S, Di Mario F, Regolisti G, Cantarelli C, Fiaccadori E. A guide to understanding antimicrobial drug dosing in critically ill patients on renal replacement therapy. Antimicrob Agents Chemother. 2019;63(8):e00583-e619.

31. Giles LJ, Jennings AC, Thomson AH, Creed G, Beale RJ, McLuckie A. Pharmacokinetics of meropenem in intensive care unit patients receiving continuous veno-venous hemofiltration or hemodiafiltration. Crit Care Med. 2000;28(3):632-7.

32. Chaijamorn W, Rungkitwattanakul D, Pattharachayakul S, Singhan W, Charoensareerat T, Srisawat N. Meropenem dosing recommendations for critically ill patients receiving continuous renal replacement therapy. J Crit Care. 2020;60:285-9.

33. Chaijamorn W, Puchsaka P, Pattharachayakul S, et al. Doripenem dosing regimens in Asian critically ill patients with continuous renal replacement therapy. J Crit Care. 2019;52:233-6.

34. Shaw AR, Chaijamorn W, Mueller BA. We underdose antibiotics in patients on CRRT. Semin Dial. 2016;29(4):278-80.

35. Drusano GL. Prevention of resistance: a goal for dose selection for antimicrobial agents. Clin Infect Dis. 2003;36:S42-50.

36. Tam VH, McKinnon PS, Akins RL, Rybak MJ, Drusano GL. Pharmacodynamics of cefepime in patients with gram-negative infections. J Antimicrob Chemother. 2002;50:425-8.

\section{Publisher's Note}

Springer Nature remains neutral with regard to jurisdictional claims in published maps and institutional affiliations. 